Progressive Physics Journal
Volume 1, Nomor 1, Mei 2020
ISSN $2722-7707$ (online)
http://jurnal.fmipa.unmul.ac.id/index.php/ppj/index

\title{
Aplikasi Metode Spektrofotometri pada Klasifikasi Gas Karbon Monoksida (CO) dan Uap Bahan Bakar Petrodiesel $\left(\mathrm{C}_{14} \mathrm{H}_{30}\right)$
}

\author{
Happy Nugroho ${ }^{1, *)}$, Edhi Sarwono ${ }^{2}$, Aditya Rinaldi ${ }^{3}$ \\ 1)Program Studi Teknik Elektro, Unversitas Mulawarman, Samarinda \\ Kampus Gn. Kelua Jl. Samballiung No.9, Samarinda 75119, Kalimantan Timur, Indonesia \\ 2) Program Studi Teknik Elektro, Unversitas Mulawarman, Samarinda \\ Kampus Gn. Kelua Jl. Samballiung No.9, Samarinda 75119, Kalimantan Timur, Indonesia \\ 3) Program Studi Fisika, Unversitas Mulawarman, Samarinda \\ Kampus Gn. Kelua Jl. Barong Tongkok No.4, Samarinda 75119, Kalimantan Timur, Indonesia
}

*E-mail korespondensi: happynugroho29@gmail.com

\begin{abstract}
Gas classification techniques are often found in several applied fields such as, detection of leak gas in gas cylinders, monitoring the threshold of harmful pollutant gases in the air, health diagnostics, early detection of fire hazards, and others. This requires measurement techniques that are adaptive and robust that can dynamically capture information on changes in vapor or gas compounds contained in free air. This research has been conducted to analyze and identify the types of gas compounds, namely $\mathrm{CO}$ and petrodiesel fuel vapor (C_14 H_30). The design of this tool uses the principle of spectrophotometry and the calculation of Backprogation Neural Networks. The working principle is that light radiation in the Light Emitting Diode (LED) series, which has a wavelength range of $385 \mathrm{~nm}$ to $1720 \mathrm{~nm}$, is absorbed to penetrate CO gas or petrodiesel fuel vapor (C_14 $\mathrm{H} \_30$ ) that you want to identify. Light radiation that has passed through the gas / vapor compound was captured by the photodiode sensor. The emission of LED series light radiation produces different wavelength absorption patterns that will be processed by the Backprogation Neural network as an input signal in the identification and learning process. The results of this experiment show the success rate of the Backpropagation neural network in identifying the type of $\mathrm{CO}$ gas and petrodiesel fuel vapor $\left(\mathrm{C}_{-} 14 \mathrm{H} \_30\right)$ is $80 \%$.
\end{abstract}

Key Words: LED Series, Backpropagation, and Spectrophotometry

\section{PENDAHULUAN}

Kemajuan bidang teknologi dan ilmu pengetahuan terapan khususnya teknologi sensor, aktuator dan transduser telah mengalami perkembangan yang sangat cepat. Hal ini disebabkan banyaknya kebutuhan terhadap proses akuisisi data yang cepat, up-to-date, tepat dan akurat dalam menganalisis masalah di berbagai aplikasi, seperti pendeteksian kebocoran gas pada tabung Liquefied Petroleum Gas (LPG), monitoring ambang batas gas polutan berbahaya tersebar di udara, diagnosa kesehatan, optimalisasi industri manufaktur dan lain-lainnya. Hal ini memicu para pakar untuk dilakukan pengembangan bidang teknologi sensor-transduser dan melakukan 
percobaan dan penelitian untuk meningkatkan kualitas produk dan keselamatan jiwa agar penerapannya lebih aplikatif dan meluas ke berbagai bidang [1]. Maka dianggap perlu adanya suatu alat yang handal, adaptif, efektif, efisien, praktis, dan user-friendly untuk mendeteksi gejala peningkatan polusi udara akibat dari aktivitas perkotaan khususnya wilayah kotamadya Samarinda. Maka dengan perancangan alat dalam riset yang dilakukan ini diharapkan mampu meminimalisir risiko bencana yang dapat sewaktu-waktu muncul dan mengancam keselamatan jiwa. Hal ini dikarenakan aktivitas perkotaan (transportasi dan industri manufaktur) berkontribusi terhadap penurunan kualitas udara khususnya di wilayah Samarinda akibat dari meningkatnya penggunaan emisi pembakaran bahan bakar fosil [2]. Salah satu indikator yang digunakan untuk mendeteksi besarnya pencemaran udara dan kualitas udara adalah Indeks Standar Pencemaran Udara (ISPU). Parameter yang digunakan dalam menganalisis ISPU yaitu sulfur dioksida $\left(\mathrm{SO}_{2}\right)$, karbon monoksida $(\mathrm{CO})$, oksidan berbentuk ozon $\left(\mathrm{O}_{3}\right)$, nitrogen dioksida $\left(\mathrm{NO}_{2}\right)$, dan partikular berukuran kurang dari $10 \mu m\left(P M_{10}\right)$ [3].

Karbon monoksida $(\mathrm{CO})$ adalah gas yang bersifat racun, tidak berbau, dan tidak berwarna. $\mathrm{CO}$ akan bercampur dengan gas lain yang juga berbau sehingga akan mudah terhirup ke dalam tubuh tanpa kita sadari. Hal ini disebabkan afinitas pada hemoglobin $\left(H_{b}\right)$ dengan $\mathrm{CO}$ berkisar antara 200-250 kali lebih besar dibandingkan oksigen $\left(\mathrm{O}_{2}\right)$ [3]. Demikian halnya dengan uap bahan bakar petrodiesel $\left(\mathrm{C}_{14} \mathrm{H}_{30}\right)$ termasuk dalam salah satu parameter ISPU yang termasuk ke dalam senyawa polutan berbahaya. Salah satu metode dan pendekatan yang sedang diteliti dan telah dikembangkan dalam mendeteksi keberadaan gas $C O$ maupun uap bahan bakar petrodiesel $\left(\mathrm{C}_{14} \mathrm{H}_{30}\right)$ yakni Hidung Elektronik (electronic nose/e-Nose) [4].

Beberapa riset yang telah dilakukan untuk meningkatkan sistem pendeteksi dini khususnya senyawa polutan berbahaya, dilakukan 5 macam pendekatan dengan metode yang berbeda, antara lain pendekatan yang pertama dengan sensor kimia (Chemical sensors), yakni proses kimia antara partikel-partikel pembentuk senyawa gas/uap dengan bahan material penyusun di permukaan sensor kimia. Antara lain dengan menggunakan Quartz Cristal Microbalance (QCM) sensors [5], e-Nose berdasarkan Metal Oxide sensors [6] [7], Surface Acoustic Wave (SAW) sensors [8], dan e-Nose berdasarkan deret sensor Polymer Composite sensor [9]. Pendekatan ke-dua dengan biosensors yang dimiliki oleh sistem indera penciuman makhluk hidup mamalia, mempunyai kemampuan ideal dalam segi sensitifitas maupun selektifitasnya sebagai pendeteksi senyawa gas/uap [8]. Pendekatan ke-tiga dengan Gas Chromatography (GC) System, merupakan metode analisa berdasarkan proses penguapan bahan pengujian, baik berupa gas atau sampel pengujian lainnya yang dipanaskan terlebih dulu sehingga sifat dari bahan pengujian berubah bentuk menjadi keadaan yang tergolong gas [5]. Pendekatan ke-empat dengan sistem real-time, terbagi menjadi 2 metode, yakni metode MassSpectrometer (MS) yang prinsip kerjanya hampir sama dengan GC System; dan metode Optical Spectroscopy dimana memanfaatkan pola penyerapan panjang gelombang $(\lambda)$ yang berbeda terhadap senyawa-senyawa kimia yang diujikan dengan menerapkan hukum Lambert Beer [10] [11]; dan kemudian Pendekatan terakhir yaitu dengan Hybrid GC/Chemical Sensor System yaitu sistem dengan menggunakan metode gabungan antara GC System dan Chemical sensor [9].

Metode dan pendekatan e-Nose dirancang dalam riset ini menggunakan pendekatan Optical Spectroscopy, khususnya dengan metode spektrofotometri sebagai dasar dalam mengidentifikasi pola-pola senyawa kimia organik pada $C O$ dan uap bahan bakar petrodiesel $\left(\mathrm{C}_{14} \mathrm{H}_{30}\right)$ karena memiliki beberapa kelebihan antara lain: dapat diterapkan secara real-time, memiliki sensitifitas yang sangat tinggi, tingkat selektifitas yang baik, dan kemampuan untuk mengidentifikasi pola-pola senyawa kimia organik tanpa harus memisahkan senyawa tersebut menjadi komponen-komponen molekulnya yang lebih kecil [12].

Halaman | 2 
Metode Spektrofotometri merupakan sistem pendeteksi senyawa gas/uap menggunakan LED Array atau deret LED sebagai sumber radiasi cahayanya dan ditangkap oleh sensor fotodioda. Beberapa penelitian sebelumnya terkait metode ini telah dilakukan, yakni Deret LED yang digunakan memiliki panjang gelombang $(\lambda)$ yang berbeda agar diperoleh pola serapan yang bersifat unik dan spesifik [10][11]. Namun masih terdapat kekurangan yakni tingkat selektifitasnya yang masih rendah sehingga kemampuannya untuk mengidentifikasi sampel gas masih terbatas. Solusi dari problem tersebut yakni dengan menambah jumlah sumber cahaya yang memiliki panjang gelombang $(\lambda)$ berbeda agar pola serapan sampel gas bersifat lebih unik dan spesifik [13]. Metode ini didukung oleh jaringan syaraf tiruan (neural network) yang berfungsi sebagai pengolah data dan telah terbukti secara empiris dalam mengklasifikasikan berbagai jenis senyawa gas maupun uap tertentu [14].

Dari permasalahan di atas, maka dengan adanya riset ini dapat merancang suatu alat yang mampu mendeteksi dan mengklasifikasikan gas karbon monoksida $C O$ dan uap bahan bakar petrodiesel $\left(\mathrm{C}_{14} \mathrm{H}_{30}\right)$ sebagai langkah preventif terkait sistem pendeteksi dini bahaya penyebaran gas/uap polutan berbahaya dalam upaya menanggulangi polutan pencemaran lingkungan sehingga risiko yang ditimbulkan dapat ditekan seminimal mungkin.

\section{METODE PENELITIAN}

Perancangan aplikasi spektrofotometri dalam mengenali gas $C O$ dan uap petrodiesel $C_{14} H_{30}$ secara umum dapat dilihat pada diagram blok Gambar 1.

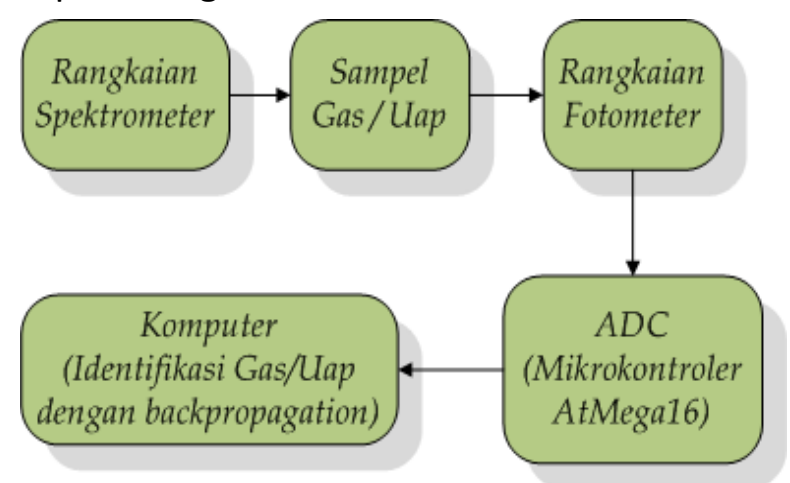

Gambar 1. Diagram Blok Sistem Identifikasi Gas/Uap

Fokus yang terpenting dalam riset ini adalah pada sistem pengenalan jenis gas atau uap pada karbon monoksida $C O$ dan uap bahan bakar petrodiesel $\left(C_{14} H_{30}\right)$ yang digunakan sebagai objek penelitian. Riset atau penelitian ini memanfaatkan prinsip spektrofotometri yang menggunakan pancaran radiasi sinar UV-IR sebagai dasar analisa proses identifikasi ke tahap selanjutnya. Secara umum, prinsip dasar dari cara kerja alat ini adalah deret LED sebagai sumber cahaya, satu per satu dinyalakan secara berurutan dan diarahkan ke chamber yang berisi gas/uap di dalamnya melalui fiber optik. Intensitas cahaya setelah melewati chamber akan bersifat unik untuk setiap gas yang ingin dianalisa. Dari setiap intensitas cahaya yang ditangkap oleh fotodioda ini akan tercatat sebagai sinyal-sinyal tegangan analog. Kemudian mikrokontroler akan mengonversi sinyal-sinyal ini ke bentuk data-data digital. Data-data ini akan dimasukkan ke komputer untuk dianalisa dan diidentifikasi sesuai jenis gas/uap yang diharapkan. Deret LED di sini berfungsi sebagai komponen spektrometer sedangkan sensor fotodioda berfungsi sebagai komponen fotometer. 
Secara keseluruhan, perancangan alat ini dibagi menjadi 5 bagian:

A. Decoder, Driver LED, dan Perancangan Deret LED

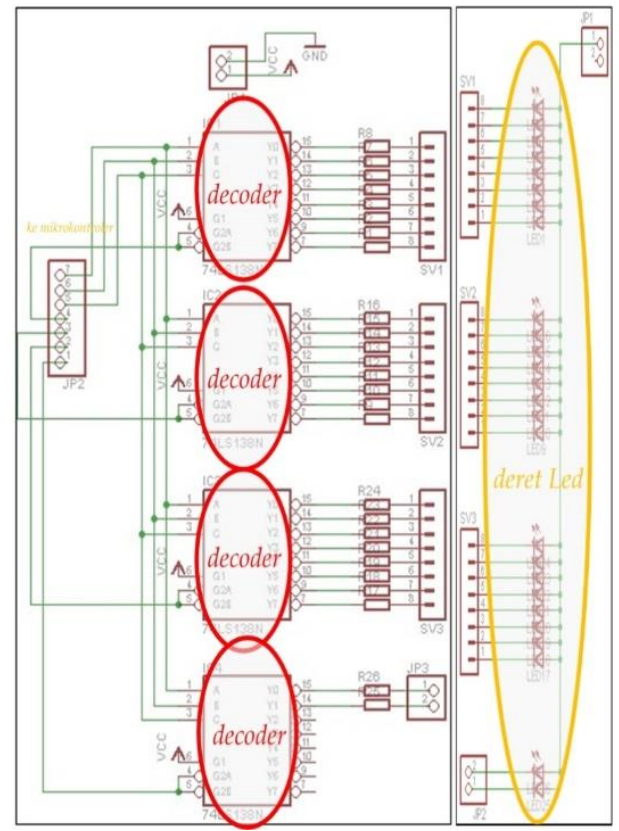

Gambar 2. Rangkaian Decoder dan Driver Deret LED

Prinsip kerja perancangan Deret LED yaitu dengan memanfaatkan sinyal keluaran dari decoder, dimana decoder yang digunakan adalah HD741LS138. Decoder berfungsi memilah sinyal masukan dari mikrokontroler untuk mengaktifkan deret LED secara bergantian. Decoder ini memiliki 8 output, 3 input dan 1 pin enable. Alat ini menggunakan 4 buah decoder dimana untuk mengaktifkan salah satu dari keempat decoder tersebut harus melalui pin enable masing-masing decoder. Ketika keluaran decoder ini memberikan sinyal low maka deret LED yang dituju akan aktif, dan begitupun sebaliknya. Perancangan decoder dan driver LED dapat dilihat pada Gambar 2. LED berjumlah 26 unit yang digunakan memiliki panjang gelombang $(\lambda)$ dengan rentang nilai antara $385 \mathrm{~nm}$ sampai dengan $1720 \mathrm{~nm}$ dengan disuplai oleh tegangan sebesar 12 volt seperti terlihat pada Tabel 1.

\section{B. Rangkaian Sensor Fotodioda dan Penguat non-Inverting}

Input dari rangkaian non-inverting ini adalah keluaran dari sensor fotodioda yang hanya memiliki rentang tegangan 0,5 volt hingga 4,8volt. Rangkaian penguat ini dibutuhkan agar pola yang terbentuk oleh tegangan keluaran sensor fotodioda tampak lebih jelas sehingga sistem dapat lebih megenali bahan pengujian gas/uap dengan lebih akurat.

\begin{tabular}{cccc} 
Tabel 1. Panjang Gelombang $(\lambda)$ & \multicolumn{3}{c}{ Deret LED yang digunakan } \\
\cline { 3 - 4 } No. & \multicolumn{1}{c}{ Tipe } & $\begin{array}{c}\text { Panjang } \\
\text { Gelombang }\end{array}$ & $\begin{array}{c}\text { Ukuran } \\
\text { LED } \\
(\mathrm{mm})\end{array}$ \\
\hline 1 & LED385-04 & 385 & 5 \\
2 & VL390-5-15 & 390 & 5 \\
3 & RLU395-8-30 & 395 & 5 \\
4 & VL400-5-15 & 400 & 5 \\
5 & LED405-02V & 405 & 5 \\
6 & VL415-5-15 & 415 & 5
\end{tabular}

Halaman | 4 


\begin{tabular}{clcc}
7 & LED420-01 & 420 & 5 \\
8 & VL425-5-15 & 425 & 5 \\
9 & LED430-06 & 430 & 5 \\
10 & LED435-12-30 & 435 & 5 \\
11 & ELD935-525 & 935 & 5 \\
12 & LED940-06V & 940 & 5 \\
13 & ELD-950-535 & 950 & 5 \\
14 & ELD-960-545 & 960 & 5 \\
15 & LED970-01 & 970 & 5 \\
16 & LED980-03 & 985 & 5 \\
17 & ELD-1020-525 & 1020 & 5 \\
18 & LED1050-33 & 1050 & 3 \\
19 & ELD-1060-525 & 1060 & 5 \\
20 & LED1070-03 & 1070 & 5 \\
21 & LED1200-03 & 1200 & 5 \\
22 & ELD-1300-525 & 1300 & 5 \\
23 & LED1450-03 & 1450 & 5 \\
24 & ELD-1480-525 & 1480 & 5 \\
25 & ELD-1550-525 & 1550 & 5 \\
26 & ELD-1720-535 & 1720 & 5 \\
\hline
\end{tabular}

Nilai penguatan (gain) yang digunakan pada rangkaian non-inverting sebesar 30 kali karena arus yang keluar dari fotodioda sangat kecil untuk rentang cahaya $U V$ dan $I R$ yang dikeluarkan oleh deret LED. Gambar 3 dan Gambar 4 menunjukkan desain rangkaian penguatan non-inverting dan modul rangkaian non-inverting beserta sensor fotodioda.

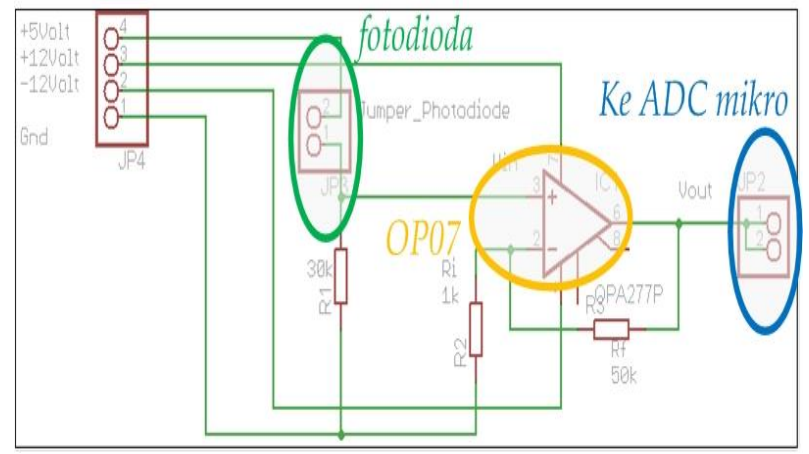

Gambar 3. Rangkaian Penguat Non-Inverting

Sensor fotodioda akan merespon perubahan intensitas cahaya yang diterima dengan mengonversinya menjadi perubahan arus pada pin keluaran (pin6) operational amplifier (OpAmp) OP07, sehingga dalam hal ini fotodioda berperan sebagai sumber arus. Semakin besar cahaya yang diterima, maka semakin besar pula arus yang dihasilkan oleh fotodioda. Arus akan dikonversi menjadi tegangan oleh resistor yang diseri $\left(R_{1}=30 \mathrm{k} \Omega\right)$ seperti terlihat pada Gambar 3. 


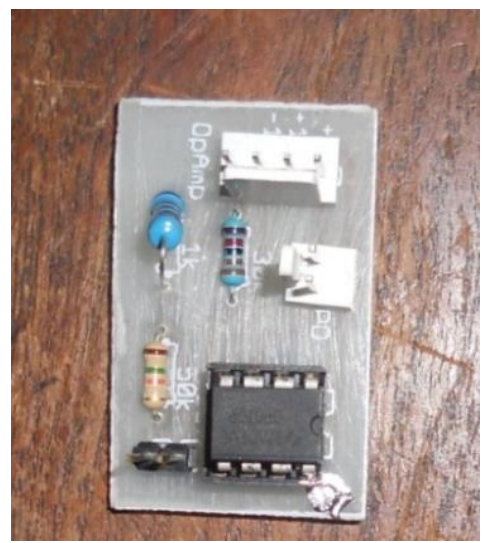

Gambar 4. Modul Rangkaian Penguat Non-Inverting dan Fotodioda

\section{Rangkaian Driver Heater}

Untuk mengatur suhu dan kelembaban chamber maka perlu dilakukan pengontrolan terhadap elemen pemanas (heater). Suhu maksimum yang dihasilkan heater mencapai $500^{\circ} \mathrm{C}$. Komponen utama pada rangkaian driver heater ini adalah MOC3021 yang di dalamnya terdapat komponen optoisolator yang berfungsi untuk mengatur proses kontrol on-off relay. Input driver heater yaitu sinyal masukan dari Port D.7 mikrokontroller AtMega16 yang merupakan output sinyal Pulse Width Modulation (PWM), dimana input tersebut memiliki rentang antara 0-5 volt. Input driver heater digunakan untuk mengatur duty cycle tegangan AC 220 volt pada heater. Gambar 5 menunjukkan elemen pemanas (heater) yang digunakan, dan Gambar 6 merupakan rangkaian driver heater.

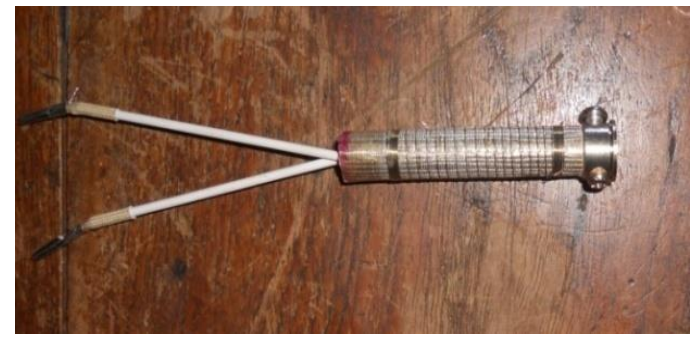

Gambar 5. Elemen Pemanas (heater)

Ketika deret LED dinyalakan bergantian, tiap nyala LED masing-masing akan dideteksi oleh fotodioda dan dikuatkan oleh penguat op-amp non-inverting. Hasil penguatan oleh Op-Amp akan dibaca dan dikirimkan ke $P C$ melalui komunikasi serial USART.
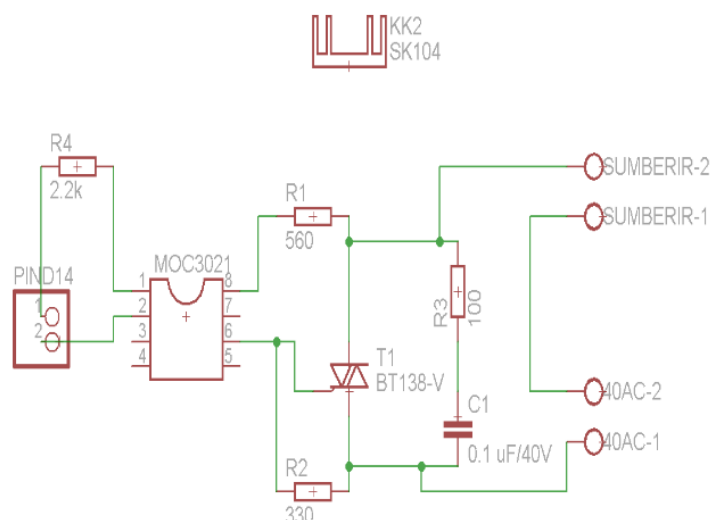

Gambar 6. Rangkaian driver heater 
D. Jenis Gas/Uap yang Diidentifikasi

Pemilihan kedua jenis gas/uap ini karena memiliki efek dari segi kesehatan yaitu membahayakan tubuh manusia apabila terhirup dalam jumlah melebihi ambang batas maksimal. Karbon monoksida $(\mathrm{CO})$ merupakan polutan berbahaya dari hasil pembakaran yang tidak sempurna pada asap kendaraan, sedangkan bahan bakar petrodiesel $\left(\mathrm{C}_{14} \mathrm{H}_{30}\right)$ merupakan bahan bakar utama mesin transportasi umum di Samarinda, yang penggunaannya terus meningkat dan berpotensi memberikan dampak negatif pada lingkungan yaitu tingginya tingkat pencemaran di udara kotamadya Samarinda akibat emisi hasil pembakaran bahan bakar fosil. Tabel 2 menunjukkan pola target bahan pengujian pada pelatihan jaringan Backpropagation.

Tabel 2. Pola Target pada Pelatihan Jaringan Syaraf Backpropagation

\begin{tabular}{clc}
\hline $\begin{array}{c}\text { No. } \\
\text { Pola }\end{array}$ & \multicolumn{1}{c}{$\begin{array}{c}\text { Sampel } \\
\text { Gas }\end{array}$} & Target \\
\hline 1 & Karbon monoksida $(\mathrm{CO})$ & 001 \\
2 & Uap Bahan Bakar Petrodiesel $\left(\mathrm{C}_{14} \mathrm{H}_{30}\right)$ & 010 \\
3 & Tak diketahui & 100 \\
\hline
\end{tabular}

E. Blok Pendistribusian Gas/Uap

Terdapat dua bagian utama pada blok ini, yaitu:

1) Tabung Chamber yang Digunakan

Bagian pertama ini yaitu chamber atau medium untuk wadah bahan pengujian, chamber terbuat dari pipa stainless berbahan material baja yang telah dilapisi oleh cairan aluminium di sisi luar dan dalamnya. Chamber ini dilengkapi dengan sensor fotodioda, heater, dan sensor suhu LM35, seperti terlihat pada Gambar 7. Sebelum melakukan proses pengambilan data, proses pengujian, dan proses identifikasi maka chamber harus dibersihkan dengan udara kering terlebih dahulu. begitu pula nilai set-point untuk suhu dalam chamber juga harus diatur terlebih dulu pada nilai set-point tertentu.

2) Perancangan Pendistribusian Gas/Uap

Pada bagian kedua ini adalah blok yang terdiri dari: tabung aquades, valve, pompa udara, tabung bahan pengujian gas/uap, dan tempat Silica Gel. Silica gel digunakan untuk memperoleh kualitas udara kering, sehingga $\mathrm{CO}$ dan uap petrodiesel $C_{14} H_{30}$ yang dimasukkan ke dalam chamber terbebas dari kandungan uap air $\left(\mathrm{H}_{2} \mathrm{O}\right)$. Keluaran dari blok ini akan masuk ke tabung chamber. Blok pendistribusian gas/uap dapat dilihat pada Gambar 8.

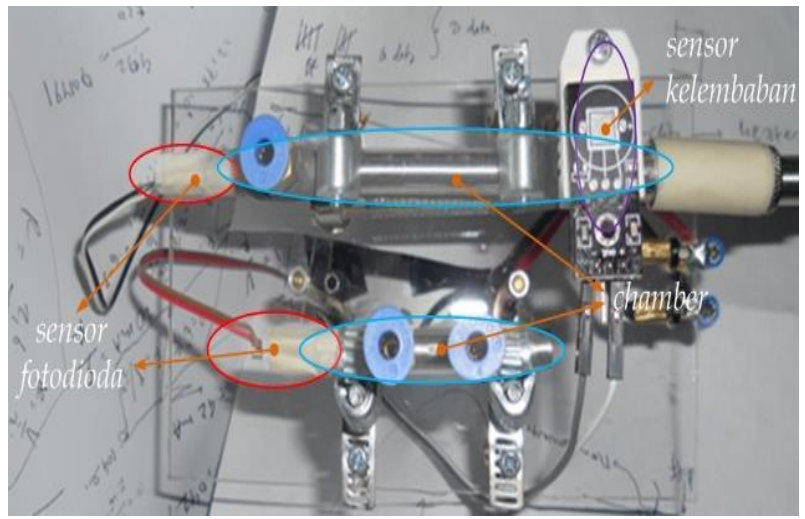

Gambar 7. Tabung Chamber 


\section{F. Jaringan Syaraf Backpropagation}

Proses pelatihan, pengujian dan pengidentifikasian yang dilakukan pada sistem ini menggunakan software Borland Delphi 7. Hasil penyerapan dari radiasi 26 jenis deret LED yang dipancarkan pada gas $\mathrm{CO}$ maupun uap bahan bakar petrodiesel $C_{14} H_{30}$ yang diidentifikasi ini ditangkap oleh sensor fotodioda, sehingga ada sebanyak 26 data yang menjadi masukan untuk jaringan syaraf backpropagation. Sejumlah 26 data tersebut merupakan hasil pembacaan fitur Analog-to-Digital $(A D C)$ pada mikrokontroler AtMega16.

Dari beberapa kali percobaan diperoleh lapisan tersembunyi pertama dan lapisan tersembunyi ke-dua memiliki jumlah neuron yang optimal sebanyak 9 unit. Sinyal keluaran Lapisan tersembunyi pertama menjadi masukan ke lapisan tersembunyi ke-dua. Keluaran sinyal dari lapisan tersembunyi ke-dua diteruskan ke lapisan output. Dan lapisan output memiliki jumlah neuron sebanyak 2 unit, yang terdiri dari gas karbon monoksida $(C O)$ dan uap bahan bakar petrodiesel $\left(\mathrm{C}_{14} \mathrm{H}_{30}\right)$, maka banyaknya neuron pada lapisan output menyesuaikan dengan banyaknya bahan pengujian gas/uap yang ingin dianalisa. Jaringan syaraf backpropagation digunakan untuk mendukung metode spektrofotometri dalam melakukan proses pengelompokan.

Prinsip kerja dari spektrofotometri adalah berdasarkan penyerapan cahaya yang berbedabeda oleh senyawa kimia organik pada rentang panjang gelombang $(\lambda)$ tertentu dengan menerapkan hukum Lambert-Beer.

Spektrofotometri digunakan untuk mengukur absorbansi maupun pemantulan dari sampel gas/cairan dalam tabung chamber transparan. Spektrofotometri melibatkan penggunaan alat yang disebut spektrofotometer, yang digunakan untuk mengukur absorbansi cahaya pada rentang $\lambda$ antara $385 \mathrm{~nm}$ sampai dengan $1720 \mathrm{~nm}$ menggunakan kontrol dan kalibrasi yang berbeda [9] [13].

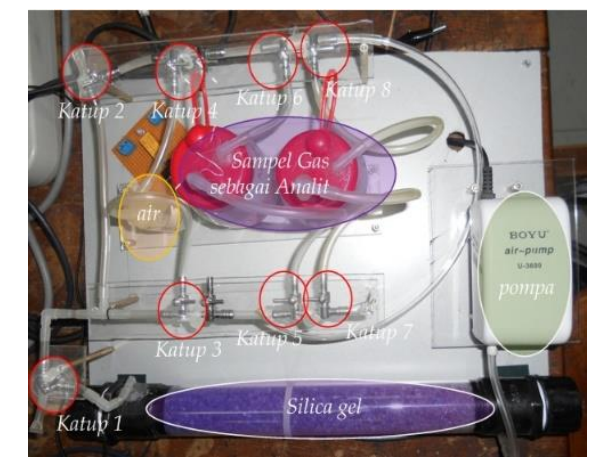

Gambar 10. Blok Pendistribusian Gas (CO) / Uap petrodiesel $\left(C_{14} H_{30}\right)$

\section{HASIL DAN PEMBAHASAN}

Hasil penelitian, pengujian, dan pembahasan yang telah dilakukan, terdiri atas:

A. Pengujian Distribusi Aliran Gas dan Uap

Pengujian terhadap pendistribusian aliran gas maupun uap dilakukan untuk mengetahui apakah saluran yang telah dirancang terjadi kebocoran atau tidak. Pengujian ini dilakukan pada beberapa titik sambungan, yakni pada beberapa valve yang terpasang seperti terlihat pada Gambar 8 sebelumnya. Tabel 3 menunjukkan pengukuran laju aliran gas dan uap. 
Tabel 3. Pengukuran Laju Aliran Gas dan Uap

\begin{tabular}{cccc}
$\begin{array}{c}\text { No. } \\
\text { Pengukuran }\end{array}$ & $\begin{array}{c}\text { Titik } \\
\text { ukur }\end{array}$ & $\begin{array}{c}\text { Tekanan } \\
\text { pompa }(\boldsymbol{L} / \\
\boldsymbol{m n t})\end{array}$ & $\begin{array}{c}\text { Pengukuran } \\
(\boldsymbol{L} / \mathbf{m n t})\end{array}$ \\
\hline 1 & valve 1 & 0,100 & 0,100 \\
2 & valve 2 & 0,100 & 0,090 \\
3 & valve 3 & 0,100 & 0,050 \\
4 & valve 4 & 0,100 & 0,070 \\
5 & valve 5 & 0,100 & 0,090 \\
\hline
\end{tabular}

Laju aliran gas dan uap diatur konstan sebesar 0,1 Liter per minute $(\mathrm{Lpm})$ menggunakan alat kalibrasi yang disebut flowmeter analog. Proses pengisian chamber dilakukan selama 3 menit, sedangkan proses pembersihan chamber dilakukan selama 7 menit. Hal ini dimaksudkan agar proses akuisisi data yang dilakukan oleh rangkaian spektrometer maupun rangkaian fotometer tidak mengalami kendala dan data yang diperoleh akurat.

B. Pengujian Rangkaian Spektrometer

Pengujian selanjutnya yakni analisis pengukuran terhadap besarnya tegangan supply pada deret LED untuk menjaga ke-optimal-an intensitas cahaya yang dipancarkan oleh masing-masing LED, seperti terlihat pada Tabel 4.

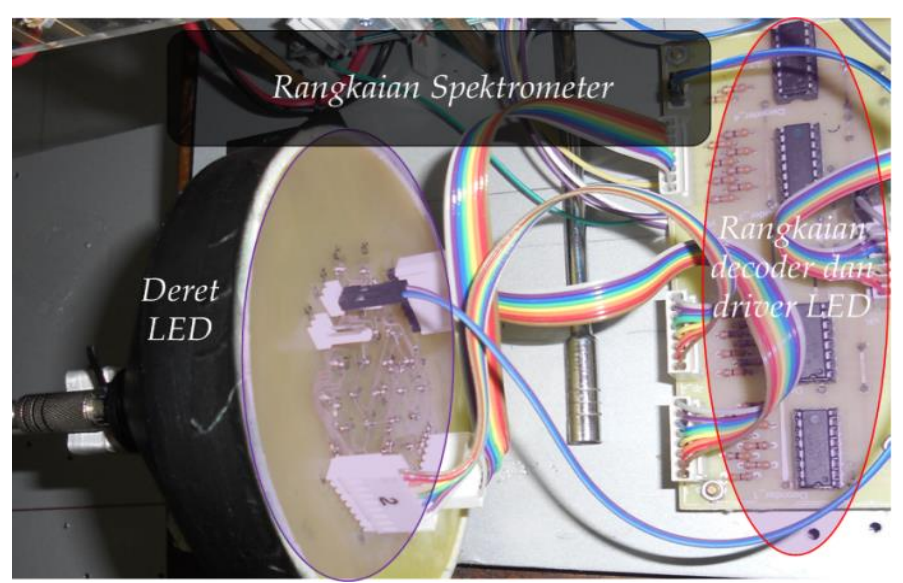

Gambar 11. Rangkaian Spektrometer 
Tabel 4. Pengukuran Tegangan Supply Deret LED

\begin{tabular}{ccc}
\hline No. & $\begin{array}{c}\text { Panjang } \\
\text { Gelombang } \\
(\text { nm })\end{array}$ & $\begin{array}{c}\text { Hasil } \\
\text { pengukuran } \\
(\text { Volt })\end{array}$ \\
\hline 1 & 380 & 3,129 \\
2 & 390 & 3,280 \\
3 & 395 & 3,700 \\
4 & 400 & 3,229 \\
5 & 405 & 5,035 \\
6 & 415 & 3,028 \\
7 & 420 & 2,918 \\
8 & 425 & 3,065 \\
9 & 430 & 3,090 \\
10 & 435 & 2,838 \\
11 & 935 & 1,140 \\
12 & 940 & 1,148 \\
13 & 950 & 1,124 \\
14 & 960 & 1,123 \\
15 & 970 & 1,12 \\
16 & 985 & 1,135 \\
17 & 1020 & 1,140 \\
18 & 1050 & 1,045 \\
19 & 1060 & 0,975 \\
20 & 1070 & 1,014 \\
21 & 1200 & 0,963 \\
22 & 1300 & 0,800 \\
23 & 1450 & 0,776 \\
24 & 1480 & 0,727 \\
25 & 1550 & 0,671 \\
26 & 1720 & 0,616 \\
\hline & &
\end{tabular}

C. Pengujian Rangkaian Fotometer

Rangkaian fotometer berfungsi untuk mendeteksi dan mengukur intensitas absorbansi cahaya pada sensor fotodioda. Komponen operational amplifier (op-amp) yang digunakan adalah IC OP07, yang merupakan jenis penguat operasional dual supply dengan menggunakan tegangan $V_{D D}$ dan $V_{E E}$ adalah \pm 12 volt. Bagian ini fokus pada pengujian rangkaian penguat non-inverting yang keluarannya akan terhubung langsung ke ADC mikrokontroler AtMega16. Pengujian penguat non-inverting penting dilakukan untuk mengetahui besar penguatan yang optimal untuk mendapatkan respon sensor fotodioda yang terbaik. Grafik pada Gambar 12 menunjukkan hasil pengujian rangkaian penguat non-inverting. 


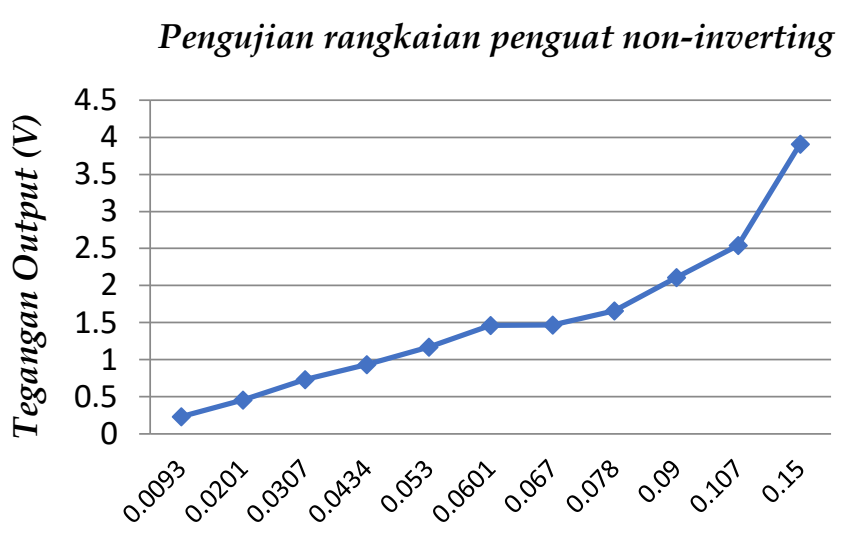

Tegangan Input (V)

\section{Gambar 12. Pengujian Rangkaian Fotometer}

Dari Gambar 12 terlihat bahwa penguatan Op-Amp non-inverting yang telah dilakukan memiliki rentang 21 kali s.d. 25 kali, meskipun penguatan yang dirancang pada rangkaian fotometer adalah sebesar 26 kali. Hal ini bisa disebabkan oleh nilai toleransi yang dimiliki pada komponen $\mathrm{R}$ dan $\mathrm{C}$ yang digunakan adalah sebesar $5 \%$. Rangkaian fotometer dapat dilihat pada Gambar 13.

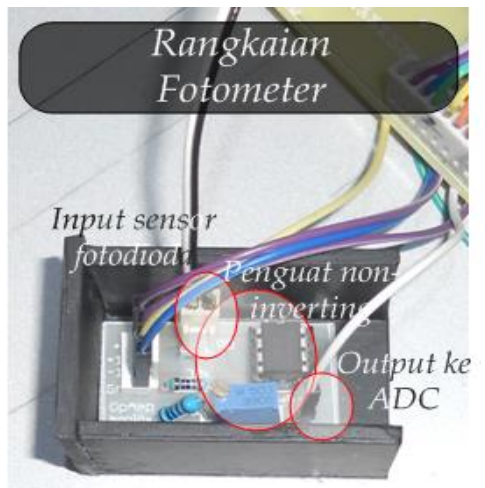

Gambar 13. Rangkaian Fotometer

D. Pengujian Karbon monoksida $(\mathrm{CO})$ dan Uap Bahan Bakar Petrodiesel $\left(\mathrm{C}_{14} \mathrm{H}_{30}\right)$

Prosedur pengujian rangkaian dilakukan dengan mengambil sampel udara kering sebagai referensi untuk mencari nilai penyerapan (absorbansi) gas karbon monoksida $(\mathrm{CO})$ dan uap bahan bakar petrodiesel $\left(\mathrm{C}_{14} \mathrm{H}_{30}\right)$. Perhitungan nilai absorbansi selanjutnya ditentukan dengan persamaan:

$$
\text { absorbansi }=I-I_{0}
$$

Keterangan:

absorbansi $=$ Besarnya penyerapan

I = Intensitas cahaya setelah melewati chamber

$I_{0} \quad=$ Intensitas cahaya sebelum melewati chamber

Dari percobaan yang telah dilakukan, diperoleh pola absorbansi intensitas cahaya terhadap gas karbon monoksida $\mathrm{CO}$ dan uap bahan bakar petrodiesel $\left(\mathrm{C}_{14} \mathrm{H}_{30}\right)$ masing-masing ditunjukkan pada Gambar 14 dan Gambar 15. 


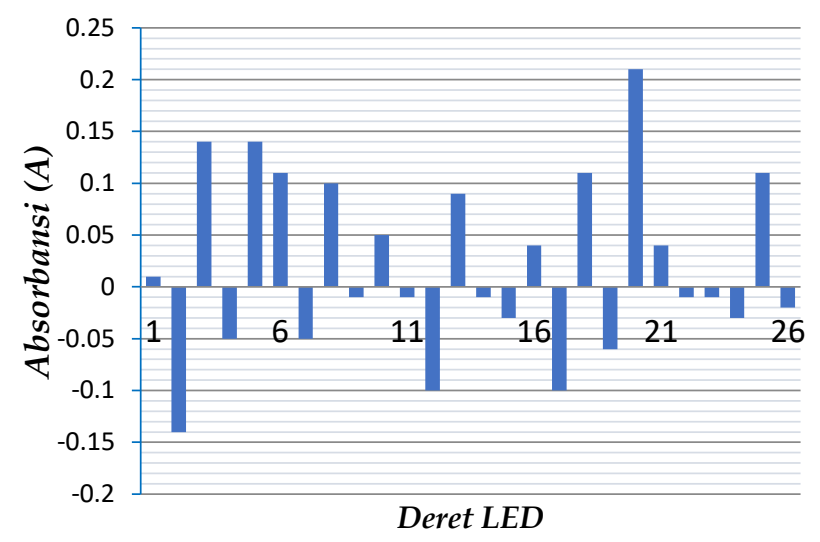

Gambar 14. Pola Absorbansi Gas $C O$

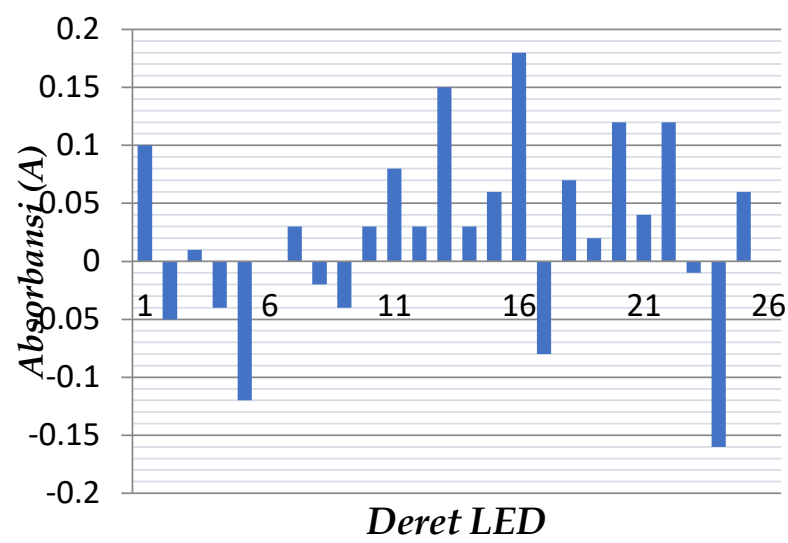

Gambar 15. Pola Absorbansi Uap Petrodiesel $\left(\mathrm{C}_{14} \mathrm{H}_{30}\right)$

Gambar 14 dan Gambar 15 merupakan respon gas/uap terhadap radiasi sinar yang dipancarkan oleh deret LED. Apabila nilai yang ditunjukkan positif, maka gas/uap tersebut menyerap cahaya, begitupun sebaliknya, apabila nilai yang ditunjukkan negatif, maka gas/uap tersebut memantulkan cahaya yang dipancarkan.

Dari Gambar 14 terlihat bahwa, LED ke-1 bernilai positif, maka gas $C O$ menyerap intensitas cahaya sinar UV dengan $\lambda$ sebesar $385 \mathrm{~nm}$. Selain itu pada LED ke-9 bernilai negatif, maka gas CO memantulkan intensitas cahaya sinar UV dengan $\lambda$ sebesar $430 \mathrm{~nm}$. Seperti halnya pada LED ke-16 bernilai positif, maka gas $C O$ menyerap intensitas cahaya sinar IR dengan $\lambda$ sebesar $985 \mathrm{~nm}$. Dan terakhir, LED ke-26 bernilai negatif, maka gas $C O$ memantulkan intensitas cahaya sinar UV dengan $\lambda$ sebesar $1720 \mathrm{~nm}$.

Berikutnya dari Gambar 15, terlihat bahwa LED ke-1 bernilai positf, maka uap petrodiesel menyerap intensitas cahaya sinar UV dengan $\lambda$ sebesar $385 \mathrm{~nm}$. Selain itu pada LED ke- 9 bernilai negatif, maka uap petrodiesel memantulkan intensitas cahaya sinar UV dengan $\lambda$ sebesar $430 \mathrm{~nm}$. Seperti halnya pada LED ke-16 bernilai positif, maka uap petrodiesel menyerap intensitas cahaya sinar IR dengan $\lambda$ sebesar $985 \mathrm{~nm}$. Dan terakhir, LED ke-26 bernilai nol, maka pada $\lambda$ sebesar $1720 \mathrm{~nm}$, uap petrodiesel ini tidak memantulkan maupun menyerap intensitas cahaya.

\section{KESIMPULAN}

Percobaan kali ini telah dilakukan perancangan sistem yang digunakan untuk mengenali dan mengidentifikasi jenis gas $(\mathrm{CO})$ dan Uap Bahan Bakar Petrodiesel $\left(\mathrm{C}_{14} \mathrm{H}_{30}\right)$ dengan 
menggunakan deret LED yang memiliki rentang panjang gelombang $(\lambda)$ antara $385 \mathrm{~nm}$ sampai dengan $1720 \mathrm{~nm}$. Pola absorbansi yang dihasilkan oleh masing-masing LED bersifat unik dan spesifik pada masing-masing gas/uap. Hasil percobaan menunjukkan bahwa sistem yang dibuat dapat mengenali jenis gas/uap dengan taraf identifikasi $80 \%$, dimana cara kerja dari sistem ini masih perlu dikembangkan agar dapat menggantikan hidung manusia, khususnya aplikasi odor yang beracun.

\section{UCAPAN TERIMA KASIH}

Terima Kasih kepada Dekan Fakultas Teknik Universitas Mulawarman, Jurusan dan Program Studi Teknik Elektro yang telah memberikan sarananya kepada penulis untuk dapat menghasilkan jurnal ini, semoga tulisan ini dapat bermanfaat kepada perkembangan teknologi di Indonesia.

\section{DAFTAR PUSTAKA}

[1] H. Nugroho, "Rancang Bangun Sistim Identifikasi Gas Menggunakan Sinar UV-IR dan Metode Jaringan Syaraf Tiruan", Tesis Magister Teknik Elektro, Istitut Teknologi Sepuluh Nopember, Surabaya, Indonesia, Jan. 2016.

[2] I. Hastuti, dan H, Sulistyarso, "Penyediaan Ruang Terbuka Hijau Berdasarkan Nilai Emisi CO2 di Kawasan Industri Surabaya", Jurnal Teknik POMITS, vol., 1, no. 1, hal. 1-5, 2012.

[3] D. Prabhandhari, "Analisis Kualitas Udara Lima Kota Metropolitan di Indonesia", Institut Pertanian Bogor, Bogor, Indonesia, Jun. 2014.

[4] M. Jamal, M.R. Khan, S.A. Imam, dan A. Jamal, "Artificial Neural Network Based E-Nose and Their Analytical Applications in Various Field", in Int. Conf. Control, Automation, Robotics and Vision ICARCV2010, 2010, hal. 691-698.

[5] M. Rivai, "Electronic Nose using Gas Chromatography Column and Quartz Crystal Microbalance", Telkomnika, vol. 9, no. 2, hal. 319-326, 2011.

[6] M. Rivai, "Sistim Diagnosa Pernapasan Menggunakan Hidung Elektronik", in Conf.InSINas, Kementerian Riset dan Teknologi, 2012, hal. 205-210.

[7] C. Wang, L. Yin, L. Zhang, D. Xiang, dan R. Gao, "Metal Oxide Gas Sensors: Sensitivity and Influencing Factors", Sensors, vol. 10, hal. 2088-2106, Mar. 2010.

[8] K. Arshak, E. Moore, G.M. Lyons, J. Harris, dan S. Clifford, "A Review of Gas Sensors Employed in Electronic Nose Applications", Sensor Review, vol. 24, hal. 181-198, 2004.

[9] S. Li, "Overview of Odor Detection Instrumentation and the Potential for Human Odor Detection in Air Matrices", MITRE Nanosystems Group and U.S. Government None-enabled Technology Initiative. McLean, Virginia: MITRE.

[10] A. Wego, "Accuracy Simulation of an LED Based Spectrophotometer", Optik, vol. 124, issue 7, hal. 644-649, 2013.

[11] T. S. Yeh dan S. S. Tseng, "A Low Cost LED Based Spectrometer", Journal of the Chinese Chemical Society, vol. 53, hal. 1067-1072, 2006.

[12] A.D. Wilson, dan M. Baietto, "Applications and Advances in Electronic-Nose Technologies", sensor, vol. 9, hal. 5099-5148, Jun. 2009. 
[13] A.G. Triantafyllou, S. Zoras, V. Evagelopoulos, S. Garas, dan C. Diamantopoulos, "DOAS Measurement Above an Urban Street Canyon in a Medium Sized City", Global NEST Journal, vol. 10, no. 2, hal. 151-168, 2008.

[14] I. Morsi, Electronic Nose System and Artificial Intelligent Techniques for Gases Identification, Data Storage, Florin Balasa, Ed. Shanghai, China: InTech, 2010. 